\title{
Impact Assessments of New Mobility Services: A Critical Review
}

\author{
Tom Storme ${ }^{1,2}{ }^{\mathbb{D}}$, Corneel Casier ${ }^{1}$ (D) , Hossein Azadi $1,3, * \mathbb{D}$ and Frank Witlox $1,4,5, * \mathbb{D}$ \\ 1 Department of Geography, Ghent University, B-9000 Ghent, Belgium; tom.storme@ugent.be (T.S.); \\ corneel.casier@ugent.be (C.C.) \\ 2 Department of Commercial Economics and Entrepreneurship, University College Ghent, \\ B-9000 Ghent, Belgium \\ 3 Faculty of Environmental Sciences, Czech University of Life Sciences Prague, 16500 Prague, Czech Republic \\ 4 Department of Geography, University of Tartu, 51014 Tartu, Estonia \\ 5 College of Civil Aviation, Nanjing University of Aeronautics and Astronautics, Nanjing 210016, China \\ * Correspondence: hossein.azadi@ugent.be (H.A.); frank.witlox@ugent.be (F.W.)
}

Citation: Storme, T.; Casier, C.; Azadi, H.; Witlox, F. Impact Assessments of New Mobility Services: A Critical Review. Sustainability 2021, 13, 3074. https://doi.org/10.3390/ su13063074

Academic Editors: Armando Cartenì and Luigi dell'Olio

Received: 27 December 2020

Accepted: 7 March 2021

Published: 11 March 2021

Publisher's Note: MDPI stays neutral with regard to jurisdictional claims in published maps and institutional affiliations.

Copyright: (c) 2021 by the authors. Licensee MDPI, Basel, Switzerland. This article is an open access article distributed under the terms and conditions of the Creative Commons Attribution (CC BY) license (https:// creativecommons.org/licenses/by/ $4.0 /)$.

\begin{abstract}
Assessing the impact of new mobility systems (e.g., shared mobility services, mobility as a service (MaaS), and Mobihubs) in urban contexts remains a challenging endeavor due to the varying priorities (social, economic, and environmental) of different stakeholders and restricted and/or limited availability of data. In a broad sense, new mobility services (NMS) can be characterized as a way of optimizing the ownership and use of a variety of mobility resources, tailored to the needs of an entire (urban) community. In this context, providing an up-to-date and critical review on the impact of NMS is the main contribution and added value of this study. To this end, this study presents an in-depth review of NMS and their diverse features (e.g., car sharing, bike sharing, Mobihubs, etc.), as an alternative to privately-owned travel modes. By reviewing more than 100 relevant sources from academic journals (Google Scholar, Science Direct, and Web of Science) and media reports, this study explains the key elements on how to address the impact assessment of NMS in terms of social, environmental, and economic aspects of sustainable mobility services. This study concludes that the implementation of NMS offers the potential to promote efficiency, sustainability, social equity, and quality of life. The main findings of this study serve as a perfect starting point for mobility providers and policymakers who are concerned about the growing demands for clean and green cities.
\end{abstract}

Keywords: new mobility services (NMS); impact assessment; social, environmental, and economic aspects; shared mobility; MaaS; Mobihubs

\section{Introduction}

The demand for new and innovative solutions to enhance their efficiency has increased in parallel with growing pressure on urban passenger transportation systems. Other pressures such as rapid urbanization, congestion, and pollution are just a few of the examples that have given rise to this wave of transportation innovation. It is therefore time to rethink the problems caused by urban mobility [1]. With increasing pressure on urban passenger transportation systems, the demand for new and unique solutions to increase their performance has increased. New mobility services (NMS) (e.g., mobility as a service (MaaS), Mobihubs, shared mobility concepts, and smart bike solutions) are therefore part of an incremental shift in travel behavior toward a multimodal system, particularly in urban areas [2]. In fact, they are effectively contributing to mobility evolution and healthy, clean, spacious, accessible, and livable cities. By definition, NMS refer to public and private transportation services that are mostly available on-demand and are generated and run by mobile technology and real-time location data. In fact, MaaS and shared mobility concepts (e.g., car sharing, bike sharing, smart bike, ride hailing, scooters, e-scooters, ebikes, Mobihubs, etc.) are categorized under NMS. The implementation of such concepts in NMS is a game changer that could considerably modify the current mobility system and, therefore, has a significant impact on society and the way we use our public space [3]. Car 
sharing, ride hailing, ride sharing, microtransit, and bike sharing are some examples of NMS currently being developed $[4,5]$. Each type has specific fundamental service features and business models that is discussed in the following sections.

Therefore, interest in NMS has grown significantly in recent years [3,4], not only because of the local increase in transportation-generated negative externalities [5] but also due to the latest new technologies' solutions, particularly in the urban context [3,6,7]. NMS are user-centric, focusing on general aspects, and responsive to the needs, habits, and preferences of travelers and society. They allow customers to gain access to transportation services on demand and for short- and long-term periods $[1,8]$. Furthermore, the differences between public transportation and private ownership are often blurred by NMS.

The emergence of NMS over the past decade has changed the urban mobility landscape and offers a wider range of individual mobility solutions $[4,9,10]$. Therefore, a proper analysis of the risk potential and NMS of an innovative technology, as well as the resulting opportunities for society, is vitally important in order to make strategic decisions in both politics and industry [11]. In this way, we need, first and foremost, an enabling method in the technological aspect of NMS that makes the NMS product more affordable and accessible to a wider population. For example, the user must pass a qualification process in the case of car sharing once. This may not be convenient for some, or vehicles can normally be obtained from distributed sites throughout a service area. In other words, vehicles can be accessible from a small number of old car rental locations (e.g., airports) [12].

NMS can be viewed as the crucial tools of urban mobility policies and sustainability, focusing on the environmental aspect. In the urban environment, the expansion of infrastructure is almost never an option and not a sustainable long-term solution. Furthermore, it is not cost-effective, there is a lack of space, and it creates environmental problems. Thus, citizens are willing to have customized and flexible solutions rather than strictly regulated public transportation. During the last decade, environmental characteristics have attracted growing attention; therefore, it is compulsory to focus on the environmental impact assessment of NMS [13]. The main focus of the policies associated with new and sustainable mobility services is on protecting the environment and climate change. In this way, sustainable mobility attempts to minimize the environmental impacts and increase climate change mitigation. It is worth mentioning that the reduction of pollutant emissions and greenhouse gases is the main goal of most interventions focusing on sustainable mobility development [14-17].

Gompf et al. (2020) [5] stated that there are new mobility solutions based on shared use that all have resulted from the ongoing efforts toward climate change mitigation and quality of life improvements in cities. They concluded that these ongoing efforts lead to a considerable effect on the use of vehicles. In a review study by Machado et al. (2018) [1] on NMS including shared transportation modes, it was stated that considering the high and increasing motorization rates, solely the emergence of shared modes is not capable of mitigating the transportation problems in large cities. It can, however, help solve the situation of congestion and pollution by decreasing the number of vehicles in circulation and urban emissions among the strategies that are being employed. Along with increasing the mobility services in cities worldwide, the issue automatically arises that mobility services can lead to more sustainable transportation options and thus to a better quality of life. To achieve this goal, taking all three sustainability dimensions (economic, environmental, and social) into account is vital. For example, improvements in environmental impacts could lead to adverse social consequences. This is important in order to prevent burden shifts [5].

Since NMS are relatively a new concept, there are few scientific publications exploring impact assessments of such mobility services in terms of social, environmental, and economic aspects of sustainable mobility services [6,9]. Therefore, the novelty of this study refers to providing an up-to-date and critical literature review on the impact of NMS in cities' context that can highlight the main contribution and added value of this study. This review study involves the main concepts of NMS (e.g., shared mobility concept, Mobihubs, and MaaS 
platforms) in urban contexts. In addition, this study explains the key elements on how to address the impact assessment of NMS in terms of social, environmental, and economic aspects of sustainable mobility services by reviewing 110 relevant sources from scholarly journals and media reports. This study ultimately attempts to answer the following question: "What are the main social, environmental, and economic contributions of NMS to sustainable mobility services?" The remainder of this paper is organized into six sections. The next section presents a detailed outline of the overview of NMS; this is followed by the methodology used. The remaining sections refer to the impact assessment of NMS in terms of social, environmental, and economic aspects and discussion on the NMS impact assessment. The final section concludes the main remarks and presents policy implications.

\section{Overview of New Mobility Services}

Mobility is at the core of the urban sustainable development and transportation policies that are established in cities $[1,8,12]$ that increasingly integrate social, economic, and environmental components $[12,18]$. Given that about $50 \%$ of the world's population lives in cities, society is looking for alternatives to address the challenges of urbanization. Over the last decades, a large number of passenger transportation options have been developed, which are called mobility services. Such mobility services have been suggested as a promising option for addressing current challenges [5]. Compared to established means of transportation, NMS has been categorized as more efficient, predictable, reliable, useful, accessible, and seamlessly connected, as well as offering easier payment options $[4,19]$. NMS also contribute to reducing the demand for parking, pollution, and traffic jams, and for users, they save energy and transportation costs. Each of these NMS aligns with a particular niche, but they also partly overlap with each other and with means of transportation that have been established. The main issue here is which service is best for a given trip, depending on the distance of the trip and the amount of flexibility (time-available destinations) during the trip.

NMS development and implementation are a process that is incorporated in both formal and informal institutional settings, which require institutional changes within and between different organizations at many different levels [4]. Here, the focus is on a collection through institutional contexts of fairly stable formal and informal rules and practices. In the context of NMS, the focus on the institutional settings is motivated by their absence in the development of policy or general strategies in which institutions are often considered as a "given" condition or reduced to a static constraint. As a result, the knowledge about the inherent diversity and complexity of institutions is still insufficient [20]. In order to understand the prerequisites for NMS, we need to know how an action is possible in relation to formal and informal institutional characteristics. In this regard, Scott (2014) [21] and Niemann (2013) [22] point out that the potential of policy-making actors is often multifaceted. This role, for instance, could be a professional identity, such as a provider of public transportation, a car rental company, or a policymaker for transportation. It should be noted, however, that institutions are changing and developing and that local adaptability to reforms is at different levels, highlighting the dynamic and contextual characteristics of the organizations [20].

\subsection{Shared Mobility Services}

The concept of shared mobility services has grown over the last few decades on how to integrate such services into urban transportation systems and make them more effective from a social, economic, and environmental point of view $[1,8,18,23]$. The sharing of the vehicle rather than private ownership and connecting users and providers using technology are the primary bases of the shared mobility services [8]. Shared mobility services can make an important contribution to achieving key urban mobility objectives. Shared mobility can lead to significant improvements quickly and at relatively low technologies' risks [24]. In addition, shared mobility services are transforming the traditional transportation industry, as they have the disruptive potential to generate a shift through the use 
of technology toward social, environmental, and economic efficiency [1]. Nonetheless, new shared mobility services can generate both positive and negative externalities. As for positive externalities, with new forms of taxation, the new tax revenue could be generated from new services. However, the use of data by new providers of mobility is at the core of marketplace control $[8,25]$. The negative externalities of shared mobility vary depending on the service model, local attributes, and time of day. Indeed, to fully understand the effects, more research is required [26]. The increasing levels of car ownership and the dominant preference for private cars are among the key challenges for sustainable cities [27-29]. Urban policies have begun to recognize car sharing as a potential tool to tackle the challenges mentioned in the previous section. The slow-but-steady move toward shared mobility services such as car sharing and bike sharing has been one approach to address the challenges, especially in combination with traditional public transportation. Thus, there could be different integrated modes of transportation to serve as a substitute for private ownership of vehicles [28]. Significant research has been conducted on the effects of car sharing, the representation of user characteristics, and the understanding of barriers to adoption in various contexts, most of which are based on personal motives and the system's feasibility from a consumer-demand aspect $[18,27,30]$. The need for new and creative solutions to improve car-sharing productivity has increased with rising pressure on urban passenger transportation systems. These pressures include road accidents and a strong reliance on fossil fuels, which make it essential to identify the basic driving modal choice factors and the rationales behind private-car dominance. Increasing environmental concerns and high dependence on fossil fuels are putting the transportation sector under pressure. Governments have to make additional efforts to speed up the contributions toward more effective urban mobility solutions in order to achieve the ambitious environmental targets in sight [31].

Car sharing is described as a mode of shared transportation in which the same vehicle is used by several individuals $[1,28]$. The main advantage is that the individuals could enjoy using the vehicle free from the duties and costs of owning one. Normally, fuel, parking, and maintenance are provided by the car-sharing operator, and each time the participants use the car-sharing options, they pay a specific fee $[1,18]$. It is worth mentioning that sharing of vehicles has already existed for a long time, e.g., in families or between neighbors, and only recently has the uptake of commercial car sharing taken place [30].

The bike-sharing system definition is very similar to car-sharing models [1,32]. Bikesharing stations are usually concentrated in urban environments and provide one-way stationbased access (bicycles can be returned to any station) or round-trip station-based access (bicycles should be returned to the picked-up station) [1]. In a study by Shaheen and Chan (2016) [33], the history of shared mobility within the urban transportation landscape was discussed, focusing on first- and last-mile public transit connections. According to their study, bike sharing has the potential to affect public transit systems, serving as an effective and efficient first- and last-mile connection. There are some options provided by free-floating bike sharing for users, e.g., offering different types of bicycles and returning them to different locations. In recent years, bike-sharing schemes have grown in popularity across the globe. In 1965, in Amsterdam, the first development of bike sharing, known as "White Bikes" was started [34]. In Denmark, in 1991, the second generation of bicycle sharing was originally opened, requiring a refundable deposit to unlock and use a bicycle [35]. In France, in 1998, the third generation of bike-sharing system was opened to deter theft and promote the return of bicycles [34]. A highly flexible GPS and smartphone dockless system, power assistance, and easier installation are the main features of the fourth generation of bike-sharing systems [36]. It is currently possible to divide globally operated bike-sharing systems into two categories: dockless-bike-sharing and docked-bike-sharing systems. There are also a range of locations for pick-up and drop-off provided by bike sharing. It is worth mentioning that most bike-sharing operators cover the costs of storage, parking, and maintenance [37].

Over the last three decades, personal vehicle sharing has grown from a collection of local grassroots organizations to global industries $[28,29,38]$. Traditional car sharing, while 
expanding, has a small network of vehicles and locations. Peer-to-peer car sharing is the next generation of shared vehicle services that addresses barriers to capital cost growth and land use by integrating relevant technologies such as personal vehicle sharing. By increasing mobility between modes and offering greater alternatives to vehicle ownership in more geographical locations, peer-to-peer car sharing has the potential to impact the transportation industry $[38,39]$. Personal car sharing is one of the newest additions to shared-use vehicle services $[38,40]$.

There are also other types of NMS such as ride hailing, scooters, e-scooters, e-bikes, and peer-to-peer ride sharing, and other flexible and shared modes are increasing their presence in our urban landscape. To be specific, ride hailing is a mobility solution that connects passengers and local drivers using their personal vehicles. With ride hailing, the client uses an app (e.g., UBER) to book a ride. The car has a professional driver who collects the customers and drives them to their destination at an agreed meeting place [41]. Peerto-peer ride sharing is an innovative approach in which owners of vehicles temporarily rent their private cars to others [39]. This option for mobility is part of the larger shared economy based on the notion of collaborative consumption rather than ownership [42]. The smart-bike solution combines the smart data of big-data analysis and is able to connect the bike, owner, store, and cloud service to the bicycle ecosystem, which is categorized both under shared mobility systems and private owners. The main features and elements of smart-bike solutions include platforms for sharing a status on social media, smartbike accessories, cycling social-media interaction website, big-data smart cloud platform, etc. The smart bikes could be also shared by the owner through a specific platform (e.g., StadtRAD Hamburg), which is called a smart-bike-sharing system [43].

\subsection{Mobihubs}

A Mobihub is a recognizable, physical place where at least two modes of transportation are frequently interconnected. For a neighborhood, Mobihubs could be the main mobility hub, similar to train stations in cities, and they can also be easily integrated into route planning facilities [44]. There is a desirable yet type-dependent link to public transportation [44]. To be specific, a mobility hub is a location, such as a bus stop or train station, where individuals can enter or exit a mobility mode $[45,46]$. Mobihubs have a transportation-network focal point [47] that seamlessly combines multiple modes of transportation, multimodal support infrastructure, and position strategies to build activity centers that optimize the connectivity of the first/last mile [45]. Providing connectivity for urban or rural areas is the main feature. Although these transportation stops are generally readily accessible for pedestrians and cyclists, car parking is of greater significance, usually provided by park-and-ride facilities. Considering Mobihubs features, the interchange hub concept (also transportation hub) is of relevance to be discussed. An interchange hub is a place that provides a passenger with a seamless journey in a joint travel chain with distinct modes of transportation. In this concept, intermodality is necessary to integrate the various modes into one efficient mobility planning. Thus, while the Mobihubs are essentially about connectivity and dispersal to the transportation system, interchanges involve the interconnection of different transportation systems [48].

There are also a few nontransportation-related functions of Mobihubs for different neighborhoods such as automatic parcel vending machines, small shops to buy snacks, etc. Ancillary functions such as shops, restaurants, etc. are included in the nonrelated functions. Mobihubs are presenting an opportunity to integrate various sustainable transportation options to improve connectivity across different regions at a time when transportation services, infrastructure, and amenities are rapidly evolving [45,47]. Mobihubs have the potential to become a catalyst in regions aimed at protecting the environment and promoting sustainable transportation choices and organize low-emission transportation options [45].

\subsection{MaaS}

MaaS was proposed as part of the solution to common transportation challenges (e.g., transfer options, reliability, integration, etc.) $[4,7,40]$, which is considered as a new 
mobility service, and its implementation is in progress [49]. To be specific, a MaaS operator provides a variety of transportation options to satisfy a customer's request (e.g., public transportation, car or bike sharing, taxi or car rental/lease, and/or a combination of transportation services) [4,7]. One of the first comprehensive MaaS definitions was given by Hietanen (2014) [50] as follows: "a mobility distribution model in which a customer's major transportation needs are met over one interface and are offered by a service provider." Therefore, MaaS is a vision of integrating temporally efficient modes across a variety of spatial efficiencies, deployed in a geographical context, thereby improving the functionality of the transportation network $[6,49,51,52]$.

To define MaaS comprehensively, there should be at least the three following aspects. These aspects indicate the link between MaaS [53], Mobihubs, and shared mobility services [4,7], directly and indirectly: (i) MaaS is a user-centered concept [54], according to which, the individual on-demand travel needs are in line with a tailored mobility package, and (ii) MaaS is a co-modal service. The main aspect of MaaS is that the software makes many travel modes more accessible to individual users. Travel needs are fulfilled by finding the most proper integration of travel modes for the operation, and (iii) MaaS services are provided via a digital, user-friendly interface, typically a smartphone application [7]. Public transportation is the backbone of the MaaS offer services along with the other modes of service for certain trips [28]. In combining all modes of travel, MaaS offers a "big bang" approach to enabling a digital system that can be easily implemented and priced based on the time of day (to the minute), geography (by location and type of road), and modal efficiency (both spatial and temporal) [19]. Therefore, MaaS has the potential for positive social impacts [55] through both media and scholars. MaaS has also the potential to reduce environmental damage resulted from urban traffic as well as the creation of new business opportunities for the transportation industry $[7,11]$. Figure 1 has been designed by the authors to illustrate the core characteristics of MaaS based on the literature review.

\subsection{Interlinks among MaaS and Mobihubs}

MaaS creation and implementation is a process that is rooted in both formal and informal institutional settings and, as such, involves institutional adjustments at several different levels within and between various organizations [4]. MaaS offers citizens easier access to more mobility options (e.g., Mobihubs) and optimally reduces the volume of car traffic if, from a street design and urban space allocation perspective, there is also a coordinated approach toward all mobility services. In addition, it gives the opportunity for a larger number of citizens to meet their mobility needs without having to own a car. The concept behind MaaS is that, until and unless we provide them with a service that provides the benefits of convenience, reliability, and low costs, citizens will not give up private cars as their preferred mode of transportation [55], while applying intermediary MaaS integrators (IMIs) into one seamless service [6]. Part of the challenge is that setting up such an innovative integrated mobility platform means moving beyond traditional company exclusive control $[4,49]$. Although a Mobihub's main function is mobility, it could also include other services. They could, for example, provide people with opportunities to access information about neighborhood activities, bike helmet lockers, and mobile food units. A Mobihub could act as delivery and collection points and provide storage facilities when using shared cars, etc. Depending on the characteristics and needs of a neighborhood, a Mobihub may also be useful for business parks, shopping areas, or housing projects [46].

Table 1 is the result of the literature review performed by the current study, and it summarizes a few studies focusing on MaaS and shared mobility concepts. The main aspect of this table is that in the last column, the contribution of each NMS to urban mobility is discussed. As discussed by Shaheen and Cohen (2013) [38], Wittstock and Teuteberg (2019) [11], and Giesel and Nobis (2016) [30], the main contributions of the NMS include lower GHG emissions, reduced ownership of private cars, and reducing energy consumption. 


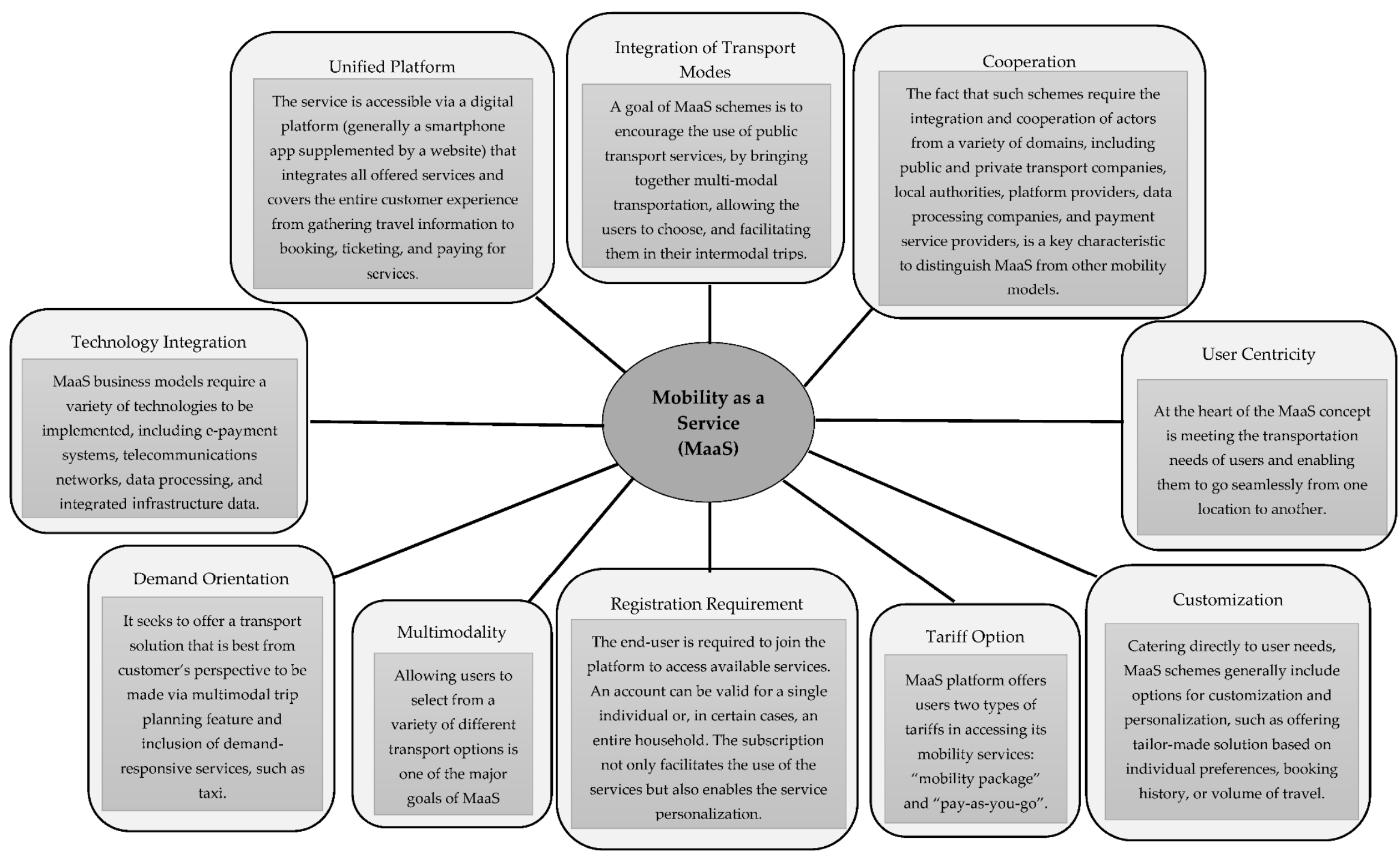

Figure 1. Core elements of MaaS schemes as derived from the literature review. Source: study findings. 
Table 1. Overview of defining MaaS and shared mobility services impacts explanations. Source: study findings.

\begin{tabular}{clll}
\hline \multicolumn{1}{c}{ Study/Year } & \multicolumn{1}{c}{ Topic } & \multicolumn{1}{c}{ Definition and Explanation } & \multicolumn{1}{c}{ NMS Impact } \\
\hline Shaheen and & $\begin{array}{l}\text { Car sharing and } \\
\text { personal vehicle } \\
\text { services }\end{array}$ & $\begin{array}{l}\text { Shased systems offer a versatile solution } \\
\text { that meets the world's diverse } \\
\text { transportation needs, while reducing } \\
\text { the negative impacts of ownership of } \\
\text { private cars. }\end{array}$ & $\begin{array}{l}\text { The impacts of car sharing are listed as environmental } \\
\text { land use, social effects, and transportation. Lower GHG } \\
\text { emissions and reduced ownership of cars and kilometers } \\
\text { of vehicles driven are environmental advantages also } \\
\text { associated with car sharing, as it transfers walking, } \\
\text { cycling, and public transit journeys. }\end{array}$ \\
\hline
\end{tabular}

Car-fleet sharing and shared mobility

Giesel and Nobis Impact of car sharing (2016) [30] on car ownership

Wittstock and

Teuteberg (2019) Sustainability impacts

[11] of Maas

MaaS reflects a very recent concept of mobility, which involves divergent core characteristics. systems are made up of new models with low GHG emissions and low energy consumption. On the consumer side, in order to combat the detrimental effects of car supremacy, car sharing seeks to minimize the use of cars as well as car ownership.

The mobility and environmental effects of car sharing are diverse and can be both positive and negative. This is also true of the influence of car sharing on ownership of private vehicles. Although car owners can shed their cars as a result of car sharing, it is also conceivable that car sharing ultimately contributes to the purchase of cars.

The influence of MaaS on overall GHG emissions within a given area must be considered to be highly debatable, as different effects may drive overall emissions in divergent directions. Similarly, new business opportunities, high levels of collaboration, and operational optimization are seen as important economic benefits for MaaS, allowing various companies to operate more profitably.

The MaaS effects are much greater when fleets of shared modes are introduced into the network. To be clearer, shared mobility and MaaS systems would allow device efficiency (travel time and cost) to be slightly increased while reducing energy consumption dramatically.

NMS are currently being developed and it is not possible to reliably measure or predict either their characteristics or the behavioral changes they make. That is why methodologies need to work with a high degree of ambiguity in order to examine the effects of these choices. Integrating a multitude of stakeholders into the discussion is a tactic to eliminate uncertainty.

P2P car sharing has the potential to be utilized in a variety of environments for land use and could be an important strategy to further stress car ownership. More importantly, P2P car sharing can reduce vehicle ownership, particularly with respect to vehicle suppression. innovative vehicle-sharing approach in which vehicle owners temporarily rent their personal cars to others.
Shaheen et al. Peer-to-peer (P2P) car (2019) [39] sharing
As it currently exists, MaaS seems to be primarily concerned with a certain segment of society, people living in the vicinity of high-quality public transportation for daily trips, as well as access to car sharing/car rental for other trips that cannot be used in public transportation.

Intermediary MaaS integrators (IMIs) are intermediate actors that assemble and distribute offers from transportation providers to MaaS providers.

Mobihubs could be a mobility hub for a neighborhood, same as what the train stations currently do for cities, and they can easily be integrated into route planning facilities.
MaaS options could potentially be more attractive in the suburban markets with existing carpool supplier systems or travel planning apps/services. However, the quality of data supplied from external sources can be a problem, as with all MaaS systems.

IMIs should only be introduced if there are essential motivations for using their services, and they should ideally be introduced to go beyond the provision and delivery of technical facilities, to have clear and identified objectives, and to be independent and capable actors.

In order to increase attractiveness and accessibility, the intermodal Mobihubs are not only an essential access point for the potential users themselves. The potential for additional demand in certain city centers, by closing the gap between the transportation stop and the surrounding area, can adapt to seasonal changes and make alternative modes of transportation attractive for additional users. 
Table 1. Cont.

\begin{tabular}{|c|c|c|c|}
\hline Study/Year & Topic & Definition and Explanation & NMS Impact \\
\hline Aono (2019) [45] & $\begin{array}{l}\text { Best practices for } \\
\text { mobility hubs }\end{array}$ & $\begin{array}{l}\text { Mobility hubs (Mobihubs) are often } \\
\text { defined as areas that are seamlessly } \\
\text { connected by a variety of sustainable } \\
\text { modes of transportation. Hubs offer } \\
\text { an opportunity to use new } \\
\text { transportation technology to increase } \\
\text { user experience and resilience, in } \\
\text { order to help cover the first and last } \\
\text { miles of travel hubs. }\end{array}$ & $\begin{array}{l}\text { Several partnerships (e.g., planning, services and } \\
\text { elements, and land development and funding) are often } \\
\text { involved in the implementation of mobility hubs. These } \\
\text { partnerships involve various stakeholders such as } \\
\text { business improvement associations, public agencies, } \\
\text { private mobility, technology companies, and private } \\
\text { operators. }\end{array}$ \\
\hline
\end{tabular}

\section{Methodology}

\subsection{Data Collection}

This review study conducted an in-depth literature review to explore the NMS impact assessments in terms of social, environmental, and economic aspects. The data were obtained from five broad and most appreciated scholarly databases: ISI Web of Science, Google Scholar, Science Direct, Scopus, and Picarta between 1986-2020. To perform the data collection, the following major keywords were used: (1) NMS, (2) MaaS, (3) Mobihubs, and (4) shared mobility services. The research focused on studies explaining specific issues linked to the abovementioned three keywords, while reducing the initial large number of papers produced from different databases. In addition, the study examined a wide range of topics (e.g., direct/indirect links between MaaS/Mobihubs and shared mobility services, defining MaaS and shared mobility services impacts, etc.) relevant to NMS, while recognizing that efforts to quantify or categorize keywords would require additional robust analysis data that were limited to this study. Overall, the current study included published papers focused only on English-written research papers published in peer-reviewed international journals. Moreover, most of the reports used for this article have been developed by international organizations, including the UN and the World Bank (e.g., $[23,56])$.

\subsection{Qualitative Assessment}

This paper presents a qualitative assessment study based on a critical literature review. The review was conducted in three main steps. In the first step, 110 original articles were collected. To do so, some inclusion criteria were applied to collect the relevant articles. Defining such inclusion criteria is very important and can influence the outcome of the review process [57]. The inclusion criteria for this study included: (1) date and source: the relevant articles were obtained from five broad and very credible scholarly databases: ISI Web of Science, Google Scholar, Science Direct, Scopus, and Picarta between 1986-2020; (2) geographic location of the studies: in the current paper, the focus was mainly on European studies as NMS concepts are practicing in these regions more considerably [58-60] as well as some other countries (e.g., Australia, US, China, etc.); (3) type of publication: the main focus was on the peer-reviewed articles, though we also collected some technical reports (e.g., insight reports and policy briefs) and web-based guidelines. We included the editorial and commentary papers as well; and (4) study type: in this paper, empirical, review articles and cross-sectional studies were considered.

In the second step, 80 original articles, which were relevant to NMS, MaaS, shared mobility, and urban mobility were re-sorted based on their title and abstract. In the third step, papers were further re-sorted based on the impact assessment of NMS in terms of social, environmental, and economic aspects of sustainable mobility services, which resulted in 52 journal articles.

Figure 2 shows all the three steps of our data collection and qualitative assessments. As shown in the figure, the qualitative analysis was implemented through three main steps. The first step was to collect a critical literature review from various sources and included the results of the articles focusing on NMS and its main concepts. The second step was 
to only choose the studies that have direct links with new mobility impacts, and the last step was to choose those studies that focused on the impact assessment of NMS in terms of social, environmental, and economic aspects of sustainable mobility services.

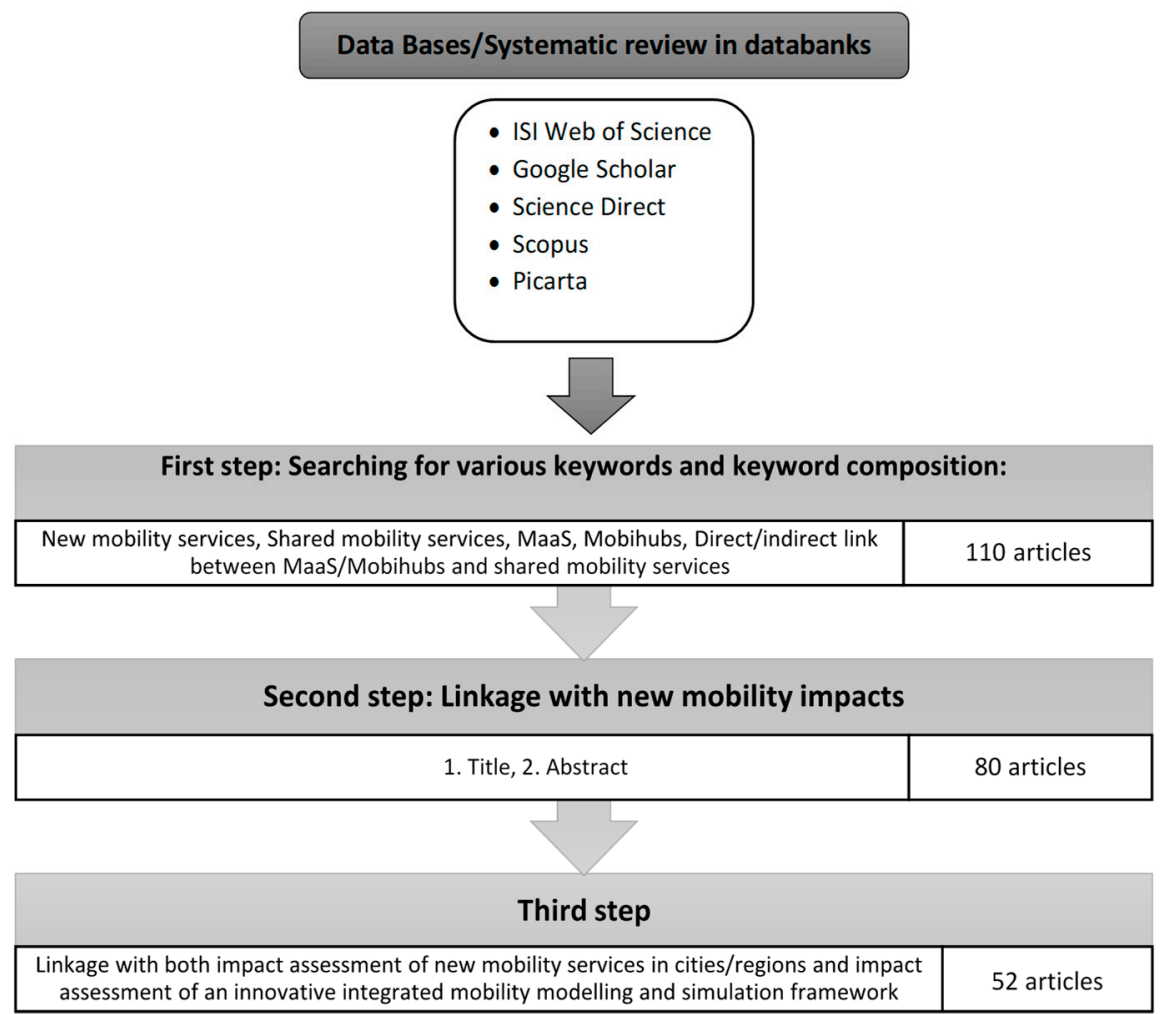

Figure 2. The main steps of data collection and analysis. Source: study findings.

\section{Impact Assessment of New Mobility Services in Terms of Social, Environmental, and Economic Aspects}

NMS are a key issue for city planners and users [3,47]. It is a rather complex task to assess the impact of NMS evolution as it involves many variables including new technologies such as MaaS and Mobihubs and new social habits such as vehicle sharing. To enhance the consistency of long-term decisions, we need a deeper understanding of various scenarios. To explore various options and to convey the results of various decisions, computer simulations might be a way to better understand this evolution $[4,47]$. There is a decline in the use of private cars and a rise in the use of public transportation. Some people, however, in some cases, still prefer NMS over public transportation. Overall, NMS replace more private car trips than public transportation trips. While the aims of the NMS are not quite the same as those of private cars or public transportation, they are partially complementary. Finally, evidence shows that NMS are commonly used in conjunction with public transit and may broaden the public transit catchment area [3]. Based on relevant studies [3,4,47], high levels of NMS implementation were more attractive to the users, and the literature review showed that the MaaS and Mobihubs had a positive impact on the demand of users. The scope of this paper is limited to three aspects of sustainable mobility services (social, environmental, and economic), but the findings provide the background and key points of NMS impact assessments that could be used by the research community to design surveys.

\subsection{Main Impacts of New Mobility Systems on Urban Transportation}

\subsubsection{Social Aspects: Safety, Security, and Accessibility}

Transportation infrastructure investment in the safety, security, and accessibility fields is the cornerstone of growth-promoting strategies [18,61]. Motorway investment, the preferred alternative for governments, yields substantially lower returns in poor institutional 
contexts than the humbler secondary path. The returns of transportation maintenance expenditure are also affected by government agencies [60]. There are increasing calls for regular monitoring and evaluation of safety, security, and accessibility strategies of new mobility operators, especially in developing countries where new mobility systems safety and security concerns abound [56,61]. Moreover, shortcomings in transportation facilities, whether in terms of capability, efficiency, protection, security, or accessibility, are closely related to higher social costs, which can hinder economic activity. For example, shared modes are generally used to replicate existing public transportation modes in the urban areas, which are at higher rates of motorization [1]. However, they can be seen as one strategy that can contribute to the reduction of circulating vehicles by mitigating the effects of traffic jams and pollution. There are therefore potential improvements to the competitiveness, efficiency, social equity, and urban quality of life through the implementation of shared mobility systems. Shared mobility solutions can bring environmental benefits and address social aspects, including modal shifts, fewer trips, distance reduction, less parking space requirements, etc. Therefore, there is a need to investigate the shared mobility impacts on transportation planning from a sustainable and urban governance perspective [27].

\subsubsection{Environmental Aspects: GHG Emissions Reduction and Livable Cities}

What follows in this paragraph refers to the impacts of practicing NMS [29,62]. By using car sharing, there are a number of benefits for policymakers including facilitating the use of existing public transportation systems, fostering higher density development, minimizing transportation energy use and greenhouse gas emissions, and reducing the need for extra highway and parking capacity [62]. Furthermore, car-sharing options have been implemented as a service that eliminates the need to purchase a private car and provides a versatile alternative to traditional car hire services in different cities. While these services do not inherently mean a decline in the use of cars, they aim to curb the ownership of vehicles. More importantly, they let drivers pay as they go. As part of their planning principles, certain low-car housing systems have adopted car sharing, thereby reducing the land take of parking facilities $[18,28]$.

Research indicates that car sharing can provide significant environmental and social benefits $[63,64]$. Such benefits include lowering GHG emissions and increasing the use of alternative forms of transportation, such as public transportation, walking, and cycling. Car-sharing cars are newer than the average personal vehicles in today's industry and have a higher average fuel economy in general [65]. Car sharing has been regarded as an effective method for demand management, capable of displacing fuel consumption that would otherwise occur in its absence, as it addresses customer mobility needs without the personal car. Walb and Loudon [66] applied the STAR assessment and found that a car was sold by $17 \%$ of the members, while $43 \%$ postponed the purchase of a vehicle. In terms of MaaS, it should also be noted that although the environmental impact of a vehicle while in use is most frequently discussed, a life-cycle perspective on vehicles should be included in order to gain a fuller understanding of the environmental impact of a vehicle [67]. This leads us to suggest that it is not enough to simply use cars with a lower environmental impact but that we need to use cars less than the other modes of transportation. Therefore, when developing MaaS, the following criteria should be considered:

- Reducing environmental impact per kilometer traveled

- Better modes of transportation than car use: walking, biking, and public transportation

- Vehicles with lower emissions per person kilometer

Evidence shows that the construction of MaaS and Mobihubs leads to a substantial reduction in the use of private cars for single occupancy and an increase in the use of public transportation, leading to a large reduction in congestion, urban air pollution, and $\mathrm{CO}_{2}$ emissions [9,54]. Such benefits take place with less private-car ownership and more shared vehicles. Under these conditions, the way people live in towns can be changed toward less traffic emission and decreasing required parking spaces. This indicates the strength of the shift and the significant benefits of increasing the use of shared mobility and the 
integrated use of different mobility services [9]. Overall, NMS impact assessment provides transportation operators with important insights into the key factors. The transportation operators should take these factors into account when implementing shared mobility, MaaS, and Mobihubs that could effectively reduce the demand for private vehicles. Researchers and transportation planners dealing with NMS should, in particular, pay attention to how different transportation operators can integrate and deliver their services as one product [54].

\subsubsection{Economic Aspects: Lower Costs and Increased GDP}

Overall, the following three factors appear to contribute to the continuing growth of shared mobility systems worldwide: (i) cost savings; (ii) convenience of location, use, and access; and (iii) awareness of the environment [38]. For example, the sharing of personal vehicles, which is defined as "short-term access to private vehicles" [26], enables the high cost of acquisition to be spread over a higher customer base. The potential economic benefits of sharing are, therefore, the greatest. In a study by Streeting and Brown (2019) [63], their results showed that by 2050, lower vehicle accident rates using NMS are a key economic benefit, improving GDP by $\$ 46$ billion AUD. About 87-89\% of this increase in GDP accounts for improved labor productivity and lower insurance costs. They also showed that in Australia, NMS could enhance employment by 200,000-274,000 full-time equivalents, or about $1-2 \%$. The proportion of total paid car business trips made by Uber in a number of cities in the United States has reached around $50 \%$, based on another study by Fischer (2019) [64], and there is some proof that this share increase reflects a decrease in the proportion of business trips made by taxi. In China, bike-sharing programs have become the most attractive investment option since 2016. The sector has reached a turning point where, due to cash limits, many small- and medium-sized dockless bike companies have gone out of business. More recently, Mobike and OfO, the first bike-sharing companies in the field, together account for almost $90 \%$ of the market [65].

\subsection{Overview of MaaS and Shared Mobility Services Impact Assessments}

In similar studies on mobility impact assessments, one way to measure the impact of NMS is to use "expert scores". This method provides us with information about transportation activities and urban mobility implications. In terms of quantitative assessments, in a study by Kilian-Yasin et al. (2016) [66], they employed a deductive quantitative survey study to explore the social acceptance of alternative mobility systems in Tunis. Using this method allowed them to identify the problems resulted from traffic flows and define the main critical points causing high amounts of $\mathrm{CO}_{2}$ emissions in the city and massive traffic jams during peak hours.

As mentioned before, we can use experts' scores as a qualitative assessment of a mobility service. A study was performed by Lopez-Ruiz et al. (2013) [18] to assess the effect of multiple policy decisions by scoring methods. These are focused on present knowledge of the effects of interventions and are not necessarily based on model estimates. Thus, using the Delphi method, the scorecards of the measures presented in these studies are typically produced. This approach allows experts to address a set of questions about the effects and consequences that according to their expert opinion, individual measures may have. In different rounds, this series of questions are answered. Average scores are obtained after each round from the responses of the experts, and these findings are shared at the beginning of the next round of questioning. In this way, individual scoring is affected by the responses of the peers of the participating experts in each round. This iterative process is carried out before the scorecards hit a convergence stage.

Schipper (2008) [67] has developed an approach to estimate transportation-related GHG emissions. This approach is called "ASIF": (A (total activity), S (modal share), I (modal energy intensity), and F (carbon content of fuels)), which is calculated as follows:

GHG $=$ Activity $\times$ modal Share $\times$ energy Intensity $\times$ carbon content of Fuels 
where GHG shows the released greenhouse-gasses emissions; activity refers to the performance of the transportation; modal share refers to freight transportation and the modal split of the passenger; energy intensity refers to the energy demand by mode of the transportation; and fuel is the carbon intensity per unit of energy demand.

There is a template to measure the abovementioned variables (total activity, modal structure, modal energy intensity, and carbon content of fuels) based on scientific literature, which is provided in Table 2. As shown in the table, a low/medium scale was used, as the values are relatively small for each measure and the impact of each measure is presented separately. In order to prepare Table 2, the scoring template should focus on the following: (1) how to avoid unsustainable transportation practices, (2) how to change unsustainable to sustainable transportation mode, and (3) how to improve current behavior in transportation activities in new mobility systems. In addition, the scoring templates should also include details on how various urban measures can affect economic, social, and environmental issues.

Table 2. Average experts' scores for measuring new mobility systems. Source: (Lopez-Ruiz et al. (2013) [18]).

\begin{tabular}{|c|c|c|c|c|c|c|}
\hline \multirow{2}{*}{ Measure } & \multicolumn{3}{|c|}{ A-S-I Effect } & \multicolumn{3}{|c|}{ E-S-E Effect } \\
\hline & Avoid & Shift & Improve & Economic & Social & Environmental \\
\hline $\begin{array}{l}\text { Maintenance and investment, including security, } \\
\text { safety, and accessibility of MaaS }\end{array}$ & Medium & Low & Medium & - & Low & Medium \\
\hline $\begin{array}{c}\text { Improvement of the efficiency of city logistics using } \\
\text { car sharing }\end{array}$ & Medium & Low & Medium & Medium & Medium & Medium \\
\hline $\begin{array}{l}\text { Measures to boost the performance of energy } \\
\text { efficiency and the environment in NMS }\end{array}$ & Low & Low & Medium & - & Low & Low \\
\hline Plans for corporate, school, and customized mobility & Medium & Low & Low & Low & Medium & Medium \\
\hline Car-sharing and bike-sharing schemes & Medium & Low & Low & - & Low & Low \\
\hline Telecommunications & Medium & Medium & Low & Low & Low & \\
\hline Parking management & Low & Medium & Medium & Low & Low & Medium \\
\hline Measures of dynamic traffic management & Low & Low & Low & Medium & Low & Low \\
\hline Ecodriving promotion & Low & Low & Low & - & Low & Low \\
\hline Low-emission zones & Low & & Medium & Low & Low & Medium \\
\hline
\end{tabular}

To wrap up this section, a quick overview of the impact assessment of NMS in terms of social, environmental, and economic aspects of sustainable mobility services has been developed as follows:

- Currently, one of the main challenges of city planners is NMS. They are changing the transportation industry, either by offering new radical solutions for mobility or by transforming conventional means of transportation with technology [3,47].

- Evidence shows that NMS are commonly used in conjunction with public transit and that the catchment area of public transit can be expanded [47].

- A major part of sustainable mobility planning is shared mobility facilities, which create jobs, foster economic growth, and encourage energy use, air quality, and $\mathrm{CO}_{2}$ emission mobility policies [48-51].

- There are increasing calls for regular monitoring and evaluation of safety, security, and accessibility strategies of shared mobility operators, especially in developing countries where mobility safety and security concerns abound [18,34,52].

- Expert scores indicate that the effect on sustainability metrics of corporate mobility strategies continues to rise over time. School mobility initiatives also seek to improve connectivity to schools by taking students to their destination in a convenient and sustainable way via bus services or by encouraging parents and teachers to carpool $[29,53]$.

- The car-sharing concept has been launched in various cities as a service that eliminates the need to purchase a private car and provides a versatile alternative to traditional car rental services [54].

- Developments in MaaS and Mobihubs contribute to a significant reduction in the use of private cars for single occupancy and an increase in the use of public transportation, leading to a significant reduction in congestion, urban air pollution, and $\mathrm{CO}_{2}$ emissions [1,55]. 


\section{Discussion: Impact Assessments of New Mobility Services Using Different Methods}

This study presented a critical literature review on different types of NMS (e.g., shared mobility, MaaS, and Mobihubs) to replicate the impact assessments of these mobility systems in terms of social, environmental, and economic aspects of sustainable mobility services. Given that NMS are an inherently dynamic and complex integrated transportation system, a coherent multiscale impact assessment should include modeling the roles, functions, behaviors, and interactions of the core NMS. Furthermore, emerging technologies would not be enough for cities and/or countries to achieve their sustainability targets, according to the literature. Indeed, much of the work concludes that achieving urban transportation sustainability requires careful urban policy planning to reduce the gap between consumer demand and green transportation supply by applying incentive tools and measures [68]. In addition, we clearly emphasize that technological development in the transportation sector is not successful unless profound organizational and behavioral improvements in the transportation sector are followed [18].

We should concentrate on the shared mobility role in reducing the number of private vehicles per family to highlight its contribution to the social aspect and on how the consumers abandon ownership of their vehicles and use shared transportation services for their convenience. However, in some studies (e.g., [69]), shared mobility has been regarded as an isolated system. In other words, the complexity of its interaction with other modes of transportation is ignored by shared mobility, which makes it very difficult to explore its impact on the transportation system. According to a study by Snelder et al. (2019) [58] and their suggested method, it can be argued that the modeling approach is an appropriate strategy to gain initial insights into the effects of shared mobility. Their suggested model consisted of new transportation and parking concepts as well as how they influence mobility options and traffic conditions.

Focusing on the economic aspect, finding access to new jobs can become relatively impossible for most unemployed people (if the neighborhood is no longer served by public transportation). However, a shift toward the growing use of shared mobility solutions could lead to a new circle of options for transit if shared mobility proves to be primarily a substitute for public transit. We have already discussed in the previous sections that there is evidence that shared mobility can lead to the achievement of desirable results from a public perspective (e.g., less pollution and congestion). For example, the time-based pricing model of car sharing is actually a form of congestion pricing, as more has to be paid by users who drive during peak hours (and thus experience longer travel times). Therefore, a wider use of car sharing would effectively "privatize" the differentiated time and location of road prices [70]. In order to promote modes like walking and cycling, the government can also promote "direct" support for car-sharing schemes. For people who otherwise rely more on their personal vehicles, enhancing investments in pedestrian and bike infrastructure can foster an environment in which car sharing is more viable.

Based on the findings of this study, there are different insights into how shared modes can help improve the transportation system's performance. To investigate current traffic problems, various modeling tools exist, but few are able to explore the effects of future mobility systems. Many of the existing instruments discuss particular concerns and are limited to the current mobility modes [47,51]. NMS are currently being developed and it is not possible to quantify or predict either their attributes or the behavioral changes they produce in an exact way. That is why approaches need to deal with a high degree of ambiguity to explore the effects of these choices. Integrating a multitude of stakeholders into the debate is a way to minimize confusion. To quickly develop, modify, and test various scenarios, modeling systems are required [47]. These findings are consistent with the findings of several studies by Becker et al. (2020) [51], Snelder et al. (2019) [58], Ho et al. (2020) [40], and Grignard et al. (2018) [47].

In the case of MaaS and its contribution to the social aspect, the actual level of cooperation within a MaaS system can, in practice, vary from one situation to another. In particular, Moovel integrates national mobility across Germany through a single smartphone platform. 
The Swedish startup Ubigo that buys operators for urban travel and then offers combined household mobility on one platform is one of the few examples of MaaS delivery of tailored services. This startup was developed to explore whether the new service concept for more sustainable urban transportation met the needs and requirements of the users. As another example, a key component of MaaS in a study conducted by Becker et al. (2020) [51] is to allow travelers to unbiasedly select modes for each journey.

In the context of social aspects of NMS impact assessments, it is worth noting that in many countries, the COVID-19 pandemic has resulted in unprecedented measures to change travel behavior [71]. Many users have begun to prefer to travel by private cars, which is not falling under the sustainability policies of urban mobility. In a study by Campisi et al. (2020) [72], their findings showed that before the COVID-19 pandemic, there had already been a positive trend in using shared mobility services and banning private cars in urban travel corridors. However, after the emergence of COVID-19, people are less likely to use shared mobility services. There are also a few survey-based studies (e.g., [73-75]) reporting that urban travel patterns were significantly influenced by the COVID-19 pandemic. During the pandemic period, the use of shared mobility decreased by $35 \%$ compared to before the pandemic, and road users became more dependent on private modes of mobility (i.e., bicycles and cars) [72].

Considering the role of MaaS in terms of economic and environmental aspects, MaaS systems field experiments showed that people make better choices in such a setup, both saving money and lowering $\mathrm{CO}_{2}$ emissions. In addition, similar findings show that shared modes can be an effective alternative for replacing bus services that are underused. In this context, the study by Ho et al. (2020) [40] highlights an important challenge linked to the integrated mobility innovator across the MaaS business model since it has been found that the effect of integrated mobility services on public preferences differs significantly from MaaS consumer category. MaaS uptake is increased by providing a pay-as-yougo alternative, but this model encourages less sustainable choices since pay-as-you-go adopters plan to retain their travel habits. A certain level of use would be assured by mobility companies, such as a car-sharing company, which can thus give subscribers more discounts as compared to pay-as-you-go users. Studies $[76,77]$ further suggest that MaaS might improve transportation system accessibility and create new economic growth opportunities. However, in MaaS cases, the number of users is small and limited. It was argued that this is because of innovation obstacles to MaaS developments (e.g., [54,78]). For example, barriers may arise within or between operational organizations.

As a final point, governments are reluctant to increase NMS market penetration at present, with the exception of the pilot projects. In other words, governments are not interested in encouraging NMS implementation. The main reason for this could be the lack of strong evidence and the range of models to show the main advantages of NMS. Another reason could be that NMS are a relatively new concept that is still progressing and that it takes more time for governments to respond $[8,79,80]$.

\section{Conclusions and Policy Implications}

This study aimed to present a critical review on NMS impact assessments in terms of social, economic, and environmental aspects as well as its different concepts (e.g., shared mobility, MaaS, Mobihubs, etc.), as an alternative to privately owned travel modes. The findings showed that NMS have begun to draw the attention of transportation consumers, the media, public authorities, and the general transportation market. NMS gain some influence over the transportation narrative through their creative ways of improving mobility. The increased use of NMS could minimize car ownership instead of using public transit, cycling, or walking for individuals who do not use a private vehicle as their primary mode of transportation. The transition to NMS would be responsible for any declines in new vehicle ownership. However, relative to the total number of transactions involving vehicles per year, these declines are likely to be very limited. The way people value, use, and think about personal vehicles is being changed by NMS. Therefore, NMS are evolving the expectations 
of the public on using vehicles. NMS would probably contribute to a change in preferences, discovering new modal shifts that do not involve the user owning a vehicle.

A number of significant policy implications have been derived by the findings of this study for public and private sector stakeholders in mobility services. These implications are related to whether NMS constitute a cost-effective alternative to conventional private and public modes of transportation from a social point of view. The implications also relate to the degree to which the future leverage of relevant policies for mitigation of GHG emissions for urban transportation should be based on NMS services. First, there are certain policy implications for the finding that the widespread deployment of NMS leads to a reduction in transportation-related $\mathrm{CO}_{2}$ emissions, in almost all cases. The most obvious barrier of NMS deployment is that long-term institutional obstacles to such deployment (which are not economically justified or contradict other policy objectives) should be eliminated altogether. More specifically, the findings showed that it is very likely that shared mobility would reduce the use of private cars much more than the use of public transportation. Therefore, not only in terms of GHG emissions but also in the form of reduced tailpipe emissions of air pollutants, the net environmental effect of shared mobility would be positive. Second, by adapting applicable regulations and policies, such as transportation subsidies, taxation policies, and public transportation concepts, the implementation of the NMS can be encouraged by law-making authorities. Thus, the positive impacts of NMS could extend to other urban externalities that result from the excess use of private cars, such as congestion, noise, and traffic accidents. Third, regional and local authorities may further contribute to developing favorable conditions for NMS by designing, for example, urban design and transportation infrastructures. The important outcome of this finding is that key policies (e.g., taxes and subsidies) should also target other (possibly more effective) ways of decarbonizing urban transportation. Fourth, in future NMS projects, private actors have an important role to play, and both public and private transportation systems are needed to make NMS a viable alternative to private cars. Fifth, NMS implementation needs funding. Support would most likely come from public or private actors, or a combination of both. Sixth, public actors may be involved in contributing to the establishment of NMS if the strategies being introduced lead to social objectives, such as greater connectivity, reduced congestion, or reduced $\mathrm{CO}_{2}$ emissions. Seventh, it is recommended to reduce the uncertainties with regard to the costs, value of time, user acceptance of NMS, and sharing concepts, by initiating pilot projects and further studying the business models to get a better understanding of the user costs. Finally, a clearer view of the transition to future and related NMS scenarios is recommended, and the impacts are subsequently assessed during the transition phase. This enables the development of adaptive policies that are needed in an era of MaaS, Mobihubs, and shared concepts of mobility.

In conclusion, in order to obtain a more in-depth understanding of NMS potential, future studies and impact assessment projects would benefit from involving a different range of mobility stakeholders and empirical information. In addition, researchers in future studies should focus not only on how NMS affect travel behavior and car ownership but also on how each NMS component affects the demand-side using model building and solving. This study focused mainly on three (social, environmental, and economic) aspects of NMS impacts assessments. Thus, future studies could also include other aspects such as legal, political, technological, and institutional aspects while assessing NMS impacts. Given the fact that the spatial focus of the current study was on urban mobility context, future studies should explore the other spatial analyses (rural, local, and pre-urban territories) of the NMS impact assessments. Moreover, considering the COVID-19 pandemic, it is a relatively new area of research to understand travel patterns and provide recommendations for using NMS during a viral pandemic based on different national contexts and global mobility indicators. The bottom line is that NMS serve as a promising mobility solution and are expected to make a major contribution to the future reform of urban mobility.

Author Contributions: Conceptualization, T.S. and H.A.; methodology, T.S. and H.A.; validation, T.S., C.C., and F.W.; formal analysis, T.S., C.C., H.A., and F.W.; investigation, T.S. and H.A.; data curation, 
T.S., C.C., H.A., and F.W.; writing-original draft preparation, T.S. and H.A.; writing-review and editing, H.A. and C.C.; supervision, F.W. All authors have read and agreed to the published version of the manuscript.

Funding: This research received no external funding.

Institutional Review Board Statement: Not applicable.

Informed Consent Statement: Not applicable.

Data Availability Statement: The data presented in this study are available on request from the corresponding author.

Acknowledgments: This paper is a result of MOBI-MIX. Improved implementation of shared mobility and MaaS to increase uptake of low-carbon transportation in cities (Interreg 2 Seas Mers Zeeën). European Regional Development Fund.

Conflicts of Interest: The authors declare no conflict of interest.

\section{References}

1. Machado, C.A.S.; de Salles Hue, N.P.M.; Berssaneti, F.T.; Quintanilha, J.A. An overview of shared mobility. Sustainability 2018, 10, 4342. [CrossRef]

2. Van Acker, V.; Goodwin, P.; Witlox, F. Key research themes on travel behavior, lifestyle, and sustainable urban mobility. Int. J. Sustain. Transp. 2016, 10, 25-32. [CrossRef]

3. Coppola, P.; Silvestri, F. Future mobility and land use scenarios: Impact assessment with an urban case study. Transp. Res. Procedia 2019, 42, 53-63. [CrossRef]

4. Karlsson, I.; Mukhtar-Landgren, D.; Smith, G.; Koglin, T.; Kronsell, A.; Lund, E.; Sarasini, S.; Sochor, J. Development and implementation of Mobility-as-a-Service-A qualitative study of barriers and enabling factors. Transp. Res. Part A Policy Pract. 2020, 131, 283-295. [CrossRef]

5. Gompf, K.; Traverso, M.; Hetterich, J. Towards social life cycle assessment of mobility services: Systematic literature review and the way forward. Int. J. Life Cycle Assess. 2020, 25, 1883-1909. [CrossRef]

6. Smith, G.; Sochor, J.; Karlsson, I.M. Intermediary MaaS Integrators: A case study on hopes and fears. Transp. Res. Part A Policy Pract. 2020, 131, 163-177. [CrossRef]

7. Storme, T.; De Vos, J.; De Paepe, L.; Witlox, F. Limitations to the car-substitution effect of MaaS. Findings from a Belgian pilot study. Transp. Res. Part A Policy Pract. 2020, 131, 196-205. [CrossRef]

8. Santos, G. Sustainability and shared mobility models. Sustainability 2018, 10, 3194. [CrossRef]

9. Forum, I.T. Transition to Shared Mobility: How Large Cities Can Deliver Inclusive Transport Services; OECD: Paris, France, 2017.

10. Costa, P.B.; Morais Neto, G.C.; Bertolde, A.I. Urban Mobility Indexes: A Brief Review of the Literature. Transp. Res. Procedia 2017, 25, 3645-3655. [CrossRef]

11. Wittstock, R.; Teuteberg, F. Sustainability Impacts of Mobility as a Service: A Scoping Study for Technology Assessment. In Progress in Life Cycle Assessment 2018; Springer: Berlin/Heidelberg, Germany, 2019; pp. 61-74.

12. Shaheen, S.; Cohen, A. Impacts of Shared Mobility. Policy Brief. 2018. Available online: https://doi.org/10.7922/G20K26QT (accessed on 20 October 2020).

13. Mestayer, P.; Abidi, A.; André, M.; Bocher, E.; Bougnol, J.; Bourges, B.; Brécard, D.; Broc, J.-S.; Bulteau, J.; Chiron, M. Urban Mobility Plan Environmental Impacts Assessment: A Methodology Including Socio-Economic Consequences-The Eval-PDU Project. In Proceedings of the 10th Urban Environment Symposium Urban Futures for a Sustainable World, Gothenburg, Sweden, 9-11 June 2010.

14. Gallo, M.; Marinelli, M. Sustainable mobility: A review of possible actions and policies. Sustainability 2020, 12, 7499. [CrossRef]

15. Van Acker, V.; Van Cauwenberge, B.; Witlox, F. MaxSUMO: A new expert approach for evaluating mobility management projects. Promet Traffic Transp. 2013, 25, 286-294. [CrossRef]

16. Semanjski, I.; Bellens, R.; Gautama, S.; Witlox, F. Integrating big data into a sustainable mobility policy 2.0 planning support system. Sustainability 2016, 8, 1142. [CrossRef]

17. Lah, O. Sustainable Urban Mobility Pathways: Policies, Institutions, and Coalitions for Low Carbon Transportation in Emerging Countries, 1st ed.; Elsevier Science: Amsterdam, The Netherlands, 2019; 308p.

18. Lopez-Ruiz, H.G.; Christidis, P.; Demirel, H.; Kompil, M. Quantifying the Effects of Sustainable Urban Mobility Plans. Report EUR 2013, 26123. Available online: https:/ / www.eltis.org/sites/default/files/trainingmaterials/quantifying_the_effects_of_ sustainable_urban_mobility_plans.pdf (accessed on 31 January 2013).

19. Wong, Y.Z.; Hensher, D.A.; Mulley, C. Mobility as a service (MaaS): Charting a future context. Transp. Res. Part A Policy Pract. 2020, 131, 5-19. [CrossRef]

20. Mukhtar-Landgren, D.; Karlsson, M.; Koglin, A.; Wendle, B. Institutional Conditions for Integrated Mobility Services (IMS).K2 Working Papers. 2016. Available online: https://portal.research.lu.se/portal/files/28465662/Mukhtar_Landgren_et_al_2016 _Institutional_conditions_for_integratmobility_services.pdf (accessed on 26 October 2016). 
21. Scott, W.R. Institutions and Organizations: Ideas, Interests, and Identities Thousand Oaks; Sage Publications: Szouzendoux, CA, USA, 2014.

22. Niemann, C. Villkorat förtroende: Normer och förväntningar I relationen mellan politiker och tjänstemän I regeringskansliet. Stockh. Stud. Politics 2013, 153, 293.

23. World Bank. Mobile Metropolises: Urban Transport Matters. An IEG Evaluation of the World Bank Group's Support for Urban Transport; The World Bank 1818 H Street NW: Washington, DC, USA, 2017; p. 20433.

24. Jiao, J. Shared Mobility. In Political Science, 1st ed.; Elsevier Science: Amsterdam, The Netherlands, 2021; 256p.

25. Lubello, V.; UB; Bousse, Y.; UITP. Review of New Mobility Services and Technologies and Set-up of Knowledge 2020. Available online: http://h2020-gecko.eu/fileadmin/user_upload/publications /GECKO_D1.1_Review_of_new_mobility_services_and_ technologies_and_set-up_of_knowledge_v1.0.pdf (accessed on 20 October 2020).

26. Shaheen, S.A. Introduction shared-use vehicle services for sustainable transportation: Carsharing, bikesharing, and personal vehicle sharing across the globe. Int. J. Sustain. Transp. 2013, 7, 1-4. [CrossRef]

27. Akyelken, N.; Givoni, M.; Salo, M.; Plepys, A.; Judl, J.; Anderton, K.; Koskela, S. The importance of institutions and policy settings for car sharing-evidence from the UK, Israel, Sweden and Finland. Eur. J. Transp. Infrastruct. Res. 2018, 18, 340-359.

28. Kamargianni, M.; Li, W.; Matyas, M.; Schäfer, A. Towards social life cycle assessment of mobility services: Systematic literature review and the way forward. Transp. Res. Procedia 2016, 14, 3294-3303.

29. Münzel, K.; Boon, W.; Frenken, K.; Blomme, J.; van der Linden, D. Explaining carsharing supply across Western European cities. Int. J. Sustain. Transp. 2020, 14, 243-254. [CrossRef]

30. Giesel, F.; Nobis, C. The impact of carsharing on car ownership in German cities. Transp. Res. Procedia 2016, 19, 215-224. [CrossRef]

31. Martinez, L.M.; Viegas, J.M. Assessing the impacts of deploying a shared self-driving urban mobility system: An agent-based model applied to the city of Lisbon, Portugal. Int. J. Transp. Sci. Technol. 2017, 6, 13-27. [CrossRef]

32. Caulfield, B.; O'Mahony, M.; Brazil, W.; Weldon, P. Examining usage patterns of a bike-sharing scheme in a medium sized city. Transp. Res. Part A Policy Pract. 2017, 100, 152-161. [CrossRef]

33. Shaheen, S.; Chan, N. Mobility and the sharing economy: Potential to facilitate the first-and last-mile public transit connections. Built Environ. 2016, 42, 573-588. [CrossRef]

34. Shaheen, S.; Zhang, H.; Martin, E.; Guzman, S. China's Hangzhou public bicycle. Transp. Res. Rec. 2011, 2247, 33-41. [CrossRef]

35. Demaio, P. Bike-sharing: History, impacts, models of provision, and future. J. Public Transp. 2009, 12. [CrossRef]

36. Gu, T.; Kim, I.; Currie, G. To be or not to be dockless: Empirical analysis of dockless bikeshare development in China. Transp. Res. Part A 2019, 119, 122-147. [CrossRef]

37. Xu, S.J.; Chow, J.Y. A longitudinal study of bike infrastructure impact on bikesharing system performance in New York City. Int. J. Sustain. Transp. 2020, 14, 886-902. [CrossRef]

38. Shaheen, S.A.; Cohen, A.P. Carsharing and personal vehicle services: Worldwide market developments and emerging trends. Int. J. Sustain. Transp. 2013, 7, 5-34. [CrossRef]

39. Shaheen, S.; Martin, E.; Hoffman-Stapleton, M. Shared mobility and urban form impacts: A case study of peer-to-peer (P2P) carsharing in the US. J. Urban Des. 2019. [CrossRef]

40. Ho, C.Q.; Mulley, C.; Hensher, D.A. Public preferences for mobility as a service: Insights from stated preference surveys. Transp. Res. Part A Policy Pract. 2020, 131, 70-90. [CrossRef]

41. Clewlow, R.; Mishra, G. Disruptive Transportation: The Adoption, Utilization, and Impacts of Ride-Hailing in the United States; Research Report UCD-ITS-RR-17-07; Institute of Transportation Studies, University of California: Berkeley, CA, USA, 2017.

42. Ballús-Armet, I.; Shaheen, S.A.; Clonts, K.; Weinzimmer, D. Peer-to-Peer Carsharing: Exploring Public Perception and Market Characteristics in the San Francisco Bay Area, California. Transp. Res. Rec. J. Transp. Res. Board 2014, 2416, 27-36. [CrossRef]

43. Rani, M.; Vyas, O.P. Smart Bike Sharing System to Make the City Even Smarter. In Advances in Computer and Computational Sciences; Bhatia, S., Mishra, K., Tiwari, S., Singh, V., Eds.; Springer: Berlin/Heidelberg, Germany, 2017; p. 553.

44. Koedood, J. Future Mobihubs as Social Connector for the Neighbourhood: About Positive Friction, Quantum Mechanics, and your Mother 2020. Available online: https: / repository.tudelft.nl/islandora/object/uuid:39e32d21-e63b-444b-8fe7-86f33ee1053e (accessed on 3 May 2020).

45. Aono, S. Identifying Best Practices for Mobility Hubs; University of British Columbia: Vancouver, BC, Canada, Opgeroepen Op Mei 2019; 2020; p. 5. Available online: https://sustain.ubc.ca/sites/default/files/Sustainability $\% 20 S c h o l a r s / 20$ 18_Sustainability_Scholars/Reports/2018-71\%20Identifying\%20Best\%20Practices\%20for\%20Mobility\%20Hubs_Aono.pdf (accessed on 14 February 2018).

46. Bell, D. Intermodal Mobility Hubs and User Needs. Soc. Sci. 2019, 8, 65. [CrossRef]

47. Grignard, A.; Alonso, L.; Taillandier, P.; Gaudou, B.; Nguyen-Huu, T.; Gruel, W.; Larson, K. The impact of new mobility modes on a city: A generic approach using abm. In International Conference on Complex Systems; Springer: Berlin/Heidelberg, Germany, 2018; pp. $272-280$.

48. Lamíquiz Daudéna, F.J.; Carpio-Pinedoa, J.; García-Pastor, A. Transport interchange and local urban environment integration. Procedia Soc. Behav. Sci. 2014, 160, 215-223. [CrossRef]

49. Pangbourne, K.; Mladenović, M.N.; Stead, D.; Milakis, D. Questioning mobility as a service: Unanticipated implications for society and governance. Transp. Res. Part A Policy Pract. 2020, 131, 35-49. [CrossRef]

50. Hietanen, S. Mobility as a Service: The New Transport Model. Eurotransport 2014, 12, $2-4$. 
51. Becker, H.; Balac, M.; Ciari, F.; Axhausen, K.W. Assessing the welfare impacts of Shared Mobility and Mobility as a Service (MaaS). Transp. Res. Part A Policy Pract. 2020, 131, 228-243. [CrossRef]

52. Hensher, D.A.; Ho, C.Q.; Mulley, C.; Nelson, J.D.; Smith, G.; Wong, Y.A. Understanding Mobility as a Service (MaaS) Past, Present and Future; Elsevier Science: Amsterdam, The Netherlands, 2020; 204p.

53. Cottrill, C.D. MaaS surveillance: Privacy considerations in mobility as a service. Transp. Res. Part A Policy Pract. 2020, 131, 50-57. [CrossRef]

54. Jittrapirom, P.; Caiati, V.; Feneri, A.-M.; Ebrahimigharehbaghi, S.; Alonso González, M.J.; Narayan, J. Mobility as a Service: A critical review of definitions, assessments of schemes, and key challenges. Urban Plan. 2017, 2. [CrossRef]

55. Wright, S.; Nelson, J.D.; Cottrill, C.D. MaaS for the suburban market: Incorporating carpooling in the mix. Transp. Res. Part A Policy Pract. 2020, 131, 206-218. [CrossRef]

56. World Bank-United Nations. Improving Trade and Transport for Landlocked Developing Countries: A Ten-Year Review; World Bank: Washington, DC, USA, 2014.

57. Meline, T. Selecting Studies for Systemic Review: Inclusion and Exclusion Criteria. Contemp. Issues Commun. Sci. Disord. Cicsd 2006, 33, 21-27. [CrossRef]

58. Snelder, M.; Wilmink, I.; van der Gun, J.; Bergveld, H.J.; Hoseini, P.; van Arem, B. Mobility impacts of automated driving and shared mobility: Explorative model and case study of the province of north Holland. Eur. J. Transp. Infrastruct. Res. 2019, 19, 291-309.

59. Akyelken, N.; Banister, D.; Givoni, M. The sustainability of shared mobility in London: The dilemma for governance. Sustainability 2018, 10, 420. [CrossRef]

60. Crescenzi, R.; Di Cataldo, M.; Rodríguez-Pose, A. Government quality and the economic returns of transport infrastructure investment in European regions. J. Reg. Sci. 2016, 56, 555-582. [CrossRef]

61. Sam, E.F.; Abane, A.M. Enhancing passenger safety and security in Ghana: Appraising public transport operators' recent interventions. J. Sci. Technol. Ghana 2017, 37, 101-112.

62. Clavel, R.; Floriet, M. The Increasing Development of Carsharing in France, European Transport Conference, 2009 Association for European Transport (AET), 2009. Available online: https://www.icscarsharing.it/wp-content/uploads/2019/02/2009-theincreasing-development-of-carsharing-in-France.pdf (accessed on 10 June 2009).

63. Streeting, M.; Brown, S. The Economic Benefits of New Mobility for Australia. 2019. Available online: https://www.lek.com/ insights / ei/economic-benefits-new-mobility (accessed on 26 August 2019).

64. Fischer, B. In Uber vs. Taxi Cab Fight, Expense Reports Offer Telling Barometer. 2015. Available online: https://www.bizjournals com/newyork/blog/techflash/2015/04/uber-taxi-expense-report-certifystudy.html (accessed on 1 November 2017).

65. Hecker, M.; Zhou, Q.; Wu, Z. The Future of Shared Mobility in China. 2016. Available online: https://www2.deloitte.com/ content/dam/Deloitte/cn/Documents/about-deloitte/dttp/deloitte-cn-dttp-vol7-ch3-future-of-shared-travel-en.pdf (accessed on 25 April 2016).

66. Kilian-Yasin, K.; Wöhr, M.; Tangour, C.; Fournier, G. Social acceptance of alternative mobility systems in Tunis. Transp. Res. Procedia 2016, 19, 135-146. [CrossRef]

67. Schipper, L. Automobile use, fuel economy and CO2 emissions in industrialized countries: Encouraging trends through 2008? Transp. Policy 2011, 18, 358-372. [CrossRef]

68. Kamargianni, M.; Li, W.; Matyas, M.; Schäfer, A. A critical review of new mobility services for urban transport. Transp. Res. Procedia 2016, 14, 3294-3303. [CrossRef]

69. Raubal, M.; Jonietz, D.; Ciari, F.; Boulouchos, K.; Küng, L.; Georges, G.; Hirschberg, S.; Schenler, W.; Cox, B.; Kannan, R.; et al. Towards an Energy Efficient and Climate Compatible Future Swiss Transportation System. Swiss Competence Center for Energy ResearchEfficient Technologies and Systems for Mobility; Working Paper Version 1.2; CCER Mobility: Zürich, Switzerland, 2017; 67p.

70. Le Vine, S.; Zolfaghari, A.; Polak, J. Carsharing: Evolution, Challenges and Opportunities, 22th ACEA Scientific Advisory Group Report. 2014. Available online: https://www.acea.be/uploads/publications/SAG_Report_-_Car_Sharing.pdf (accessed on 22 September 2014).

71. De Vos, J. The effect of COVID-19 and subsequent social distancing on travel behavior. Transp. Res. Interdiscip. Perspect. 2020, 5, 100121. [CrossRef]

72. Campisi, T.; Basbas, S.; Skoufas, A.; Akgün, N.; Ticali, D.; Tesoriere, G. The Impact of COVID-19 Pandemic on the Resilience of Sustainable Mobility in Sicily. Sustainability 2020, 12, 8829. [CrossRef]

73. Meena, S. Impact of novel Coronavirus (COVID-19) pandemic on travel pattern: A case study of India. Indian J. Sci. Technol. 2020, 13, 2491-2501. [CrossRef]

74. Beck, M.J.; Hensher, D.A. Insights into the impact of COVID-19 on household travel and activities in Australia-The early days under restrictions. Transp. Policy 2020, 96, 76-93. [CrossRef]

75. Pawar, D.S.; Yadav, A.K.; Akolekar, N.; Velaga, N.R. Impact of Physical Distancing due to Novel Coronavirus (SARS-CoV-2) on Daily Travel for Work during Transition to Lockdown. Transp. Res. Interdiscip. Perspect. 2020, 7, 100203.

76. Polis, Mobility as a Service: Implications for Urban and Regional Transport. Polis Network, Brussels. 2017. Available online: https:/ / www.polisnetwork.eu/uploads/Modules/PublicDocuments / polis-maas-discussion-paper-2017---final_pdf (accessed on 13 September 2017). 
77. MaaS Alliance, White Paper: Guidelines \& Recommendations to Create the Foundations for a Thriving MaaS Ecosystem. MaaS Alliance, Brussels. 2017. Available online: https://maasalliance.eu/wp-content/uploads/sites/7/2017/09/MaaS-WhitePaper_ final_040917-2.pdf (accessed on 1 December 2017).

78. Li, Y.; Voege, T. Mobility as a Service (MaaS): Challenges of implementation and policy required. J. Transp. Technol. 2017, 7, 95-106. [CrossRef]

79. Gurjar, J.; Jain, P.; Agarwal, P. Comparative Performance Evaluation of Public Transport Services from City Perspective. Transp. Res. Procedia 2020, 48, 2207-2229. [CrossRef]

80. Cats, O.; Susilo, Y.O.; Reimal, T. The prospects of fare-free public transport: Evidence from Tallinn. Transportation 2017, 44, 1083-1104. [CrossRef] 